\title{
EXPLOITATION OF MCDA TO LEARN THE RADIAL BASE NEURAL NETWORK (RBFNN) AIM PHYSICAL AND SOCIAL VULNERABILITY ANALYSIS VERSUS THE EARTHQUAKE (CASE STUDY: SANANDAJ CITY, IRAN)
}

\author{
Peyman Yariyan ${ }^{1}$, MohammadReza Karami ${ }^{2,}$, , Rahim Ali Abbaspour ${ }^{3}$ \\ ${ }^{1}$ Dept. of Geography Information System, Mamaghan branch, Islamic Azad University, Mamaghan, Iran - \\ peyman.yariyan@iaumamaghan.ac.ir \\ ${ }^{2}$ Dept. of Social Science, Faculty of Humanities and Social Sciences, Payame Noor University, Tehran, Iran - \\ karami_mohammadreza@ymail.com \\ ${ }^{3}$ Dept. of Surveying and Geospatial Engineering, University of Tehran, Iran - Abaspour@ut.ac.ir
}

KEY WORDS: Earthquake, MCDA, ANN, RBFNN, Sanandaj, IRAN

\begin{abstract}
:
Despite years of research on natural hazards and efforts to reduce physical and psychological damage, earthquake as a natural disaster is catastrophic. Though, human is the main axis in dealing with crisis and vulnerability, and since the space of cities encompasses largest population spectrum, managing this space is considered as an essential issue. Accordingly, the vulnerability of the City of Sanandaj was defined by environmental, physical and social criteria. In this regard, with the aim of modeling, and assessing the risk and vulnerability, the MCDA-ANN hybrid model was introduced as a new method for teaching of learning models. In order to determine the final value of each of the criteria, AHP analysis was performed as one of the MCDA methods to solve complex and non-structural problems by creating a functional hierarchy, and after that, a training data base for learning ANN was created randomly based on the AHP classification map. Then, for modeling, the radial base functional neural network (RBFNN) was used as one of the techniques of artificial neural networks. After the modeling, 30\% of the points were selected as validation data to determine the accuracy of the model. After the implementation of RBFNN model, the area of AUC curve resulted is 0.922 , which indicates the high accuracy of the model in assessing the risk of an earthquake. The results show high vulnerability in urban areas1 and 2 and in downtown Sanandaj that in these zones the physical and social factors dramatically affect the vulnerability of these areas.
\end{abstract}

\section{Introduction}

One of the main causes of urban vulnerability to earthquakes is the lack of control of urban growth, the lack of proper crisis management, and the construction of homes in risky places (Hashemi $\mathrm{M}$ et al., 2017). GIS can provide information about the dangers of buildings and critical facilities in the region and includes risk assessment programs that allow urban planners to simulate disaster scenarios (Z. C. Aye et al., 2016). In order to combine various factors and provide classified maps, artificial neural network (ANN) is a useful technology for zoning and risk assessment based on the training database, which has been used in many studies (Bouktif S et al., 2018 \& Alizadeh M et al., 2018 \& Yingying Tian et al., 2018). Artificial neural network can approach fixed nonlinear functions by balancing the outputs of each of the neurons that with the selection of enough neurons, can automatically correct the approximate errors (RaheliNamin B., 2018 \& Mollalo A et al., 2019). ANN needs a training set to be able to accurately assess the vulnerability (Pourghasemi H.R et al., 2018). Artificial neural network requires standardized factors for learning and modeling and the learning process is conducted in a strong and consistent manner (Oludare Isaac A et al., 2018 \& German I.Parisi et al., 2019). MCDA is an analytical decision-making tool that can select the right alternative (Nenadić, D., 2019). Multi-criteria decision analysis (MCDA) is a method used to combine spatial data( Morkūnaite $\mathrm{Z}$ et al., 2019). The basis for the risk assessment and modeling is the selection of effective layers. For this reason, in this research, using the opinions of engineers, researchers, previous studies and questionnaires, 13 layers from natural, physical and social criteria for modeling earthquake hazard in Sanandaj were selected. Therefore, the main objective of this study is the zoning and evaluation of physical and social vulnerability to earthquakes that using of AHP and RBFNN models, one hybrid model has been developed based on effective indicators. After editing the layers in the ARC GIS software, standardization and paired comparisons were performed. Then, using a map resulted from the AHP model along with five classes; a database of training site for learning the RBFNN model was prepared under supervision.

\section{Materials and Methods}

\subsection{Study area}

The study area in this article is Sanandaj city, which located in $\mathrm{N}, 35^{\circ} 18^{\prime} 52$ "E $46^{\circ} 59^{\prime} 32^{\prime \prime} \mathrm{E}$,in west of Iran and Kurdistan Province, with a population of 414069 and an area of 2906.04 $\mathrm{km} 2$, and due to the entity of two main faults, of this city it is at risk of earthquake.(Murgante B., 2017). Considering the topographical features of the city and its position in the mountainous region of Zagros with at an elevation of 1368 to $1357 \mathrm{~m}$, Sanandaj can be categorized as a mountainous city (Ibrahim et al., 2015). Also Sanandaj City has three urban areas, that elevation in the north and west of Zone 1 and west and southwest of Zone 3 more than other areas. 


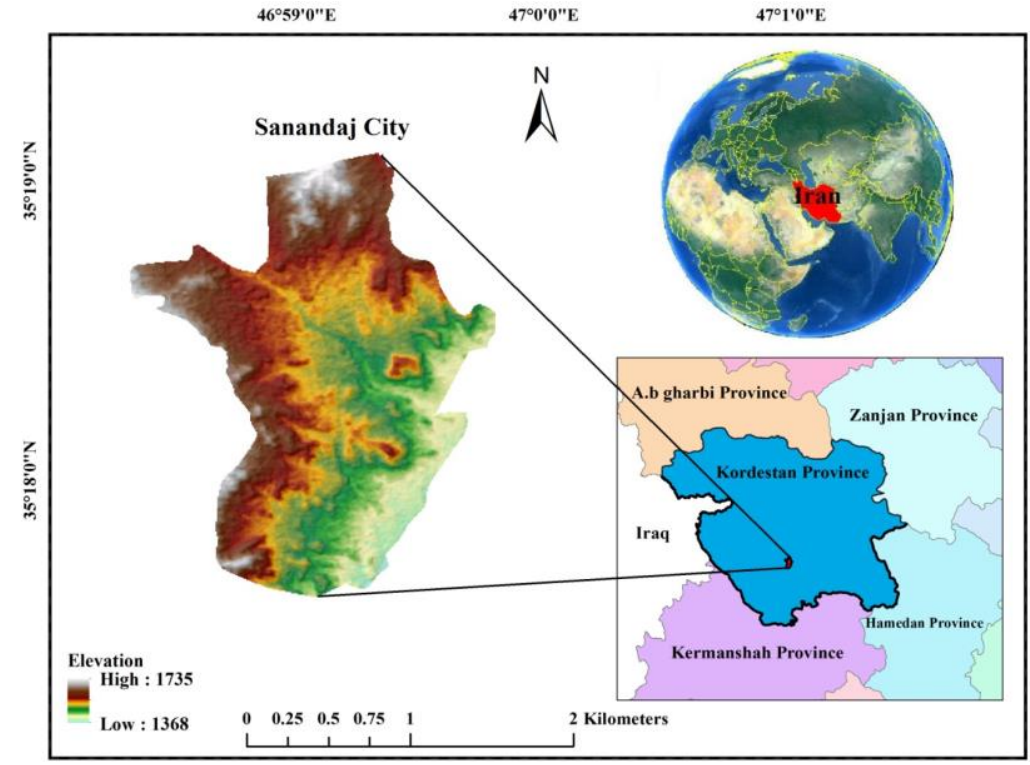

Figure 1. Location of study area

\subsection{Data Acquisition, Classification and Standardization}

In this part of the study, using the views of experts, researchers and previous studies, 5 natural layers, 6 physical layers and 2 social layers were selected as layers affecting seismic vulnerability. Then all layers were edited, classified and standardized according to the conditions of the study area in the ArcGIS software. The physical and social layers used in the study were prepared through a comprehensive plan of Sanandaj (2016) and Population Blocks (2016) , and the Environmental layers were prepared through the DEM 30-meter of the region, maps of the Geological Survey \& Mineral Explorations of
Sanandaj.Environmental layers used in research: Distance from the waterway network, distance from Fault, Slope, elevation, geology and physical layers: construction with quality materials, construction without quality materials, building area, distance from Communication centers, number of floors, land use and social layers of the population and family density, which was used with Raster format and a scale of 1: 76,000 and pixel size $(15 \mathrm{~m} \times 15 \mathrm{~m})$.

\begin{tabular}{|c|l|c|c|c|c|}
\hline Criteria & \multicolumn{1}{|c|}{ Layers } & Weights & CR & Source & Scholars \\
\hline \multirow{5}{*}{ Environmental } & Distance from the runway & 0.05 & & 1 & \\
& Geology & 0.10 & & 1 & (Ebrahimi.M et al., 2016) \\
& Distance from fault & 0.07 & 0.00086 & 2 & \\
& Elevation & 0.06 & & 2 & \\
& Slope & 0.08 & & 3 & \\
& Distance from the Road & 0.07 & & 4 & \\
& Land use & 0.07 & & 4 & (Al shabeeb A.R., 2016) \\
& Building area & 0.08 & 0.0088 & 1 & \\
& Building with quality materials & 0.08 & & 4 & \\
& Building with no quality materials & 0.08 & & 4 & \\
& Number of floors & 0.09 & & 4 & (Eleonora Giovene et al., 2017) \\
& Population density & 0.10 & & 5 & \\
& Family density & 0.07 & 0.00026 & 5 & \\
& & & & & \\
& & & & \\
& & & & \\
\end{tabular}

Table 1. Weights for Criteria and Layers based on the AHP model

Source:

1. Department of road and Urbanity. http://www.std2800.ir/ 2. DEM $30 \mathrm{~m}$ Land sat. https://www.usgs.gov/ 3. Iranian Geological organization. https://gsi.ir/ 4. The municipality of sannadaj city. http://www.e-sanandaj.ir/ 5. Census Center of Iran .https://www.amar.org.ir/. 


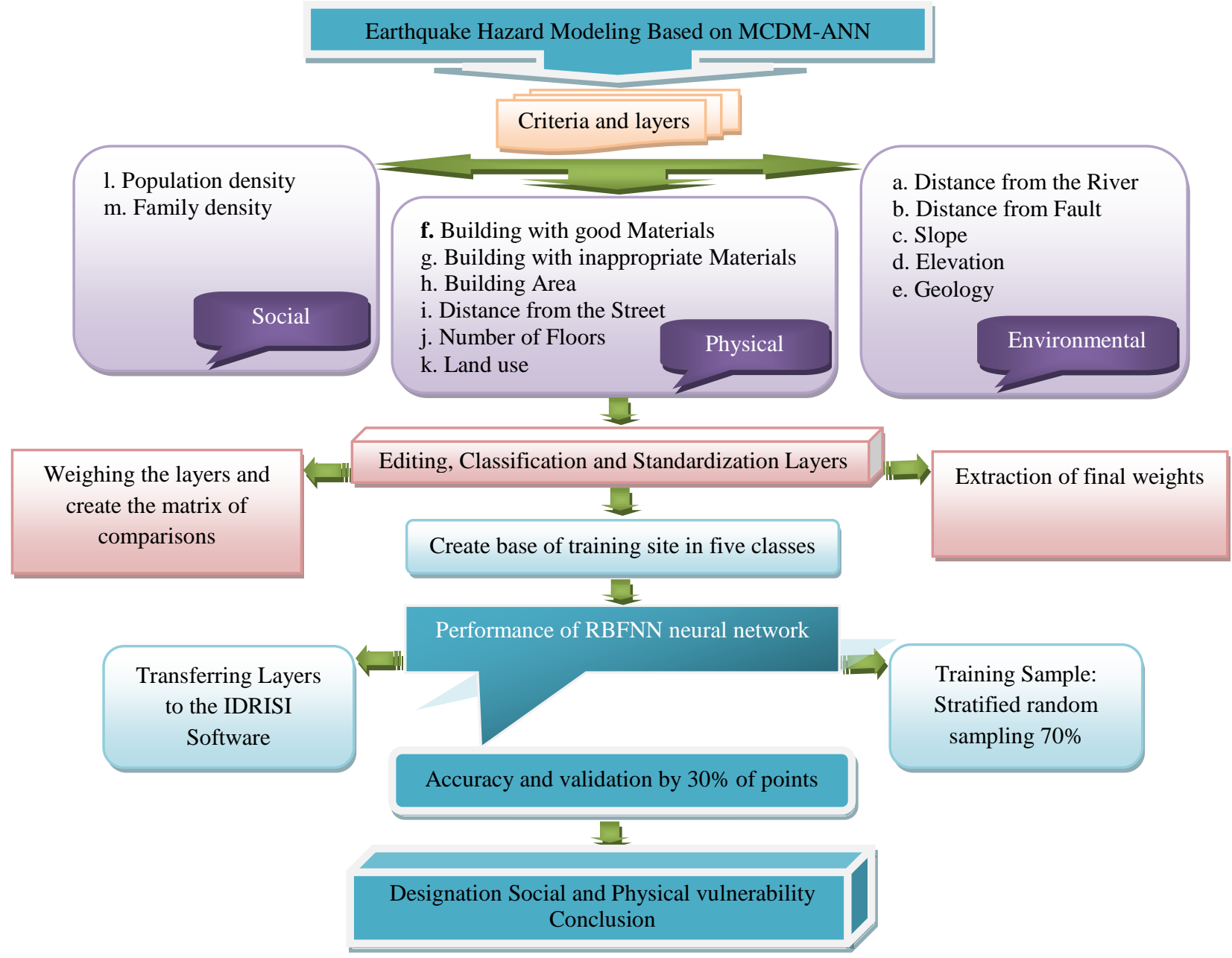

Figure 2. The process of research
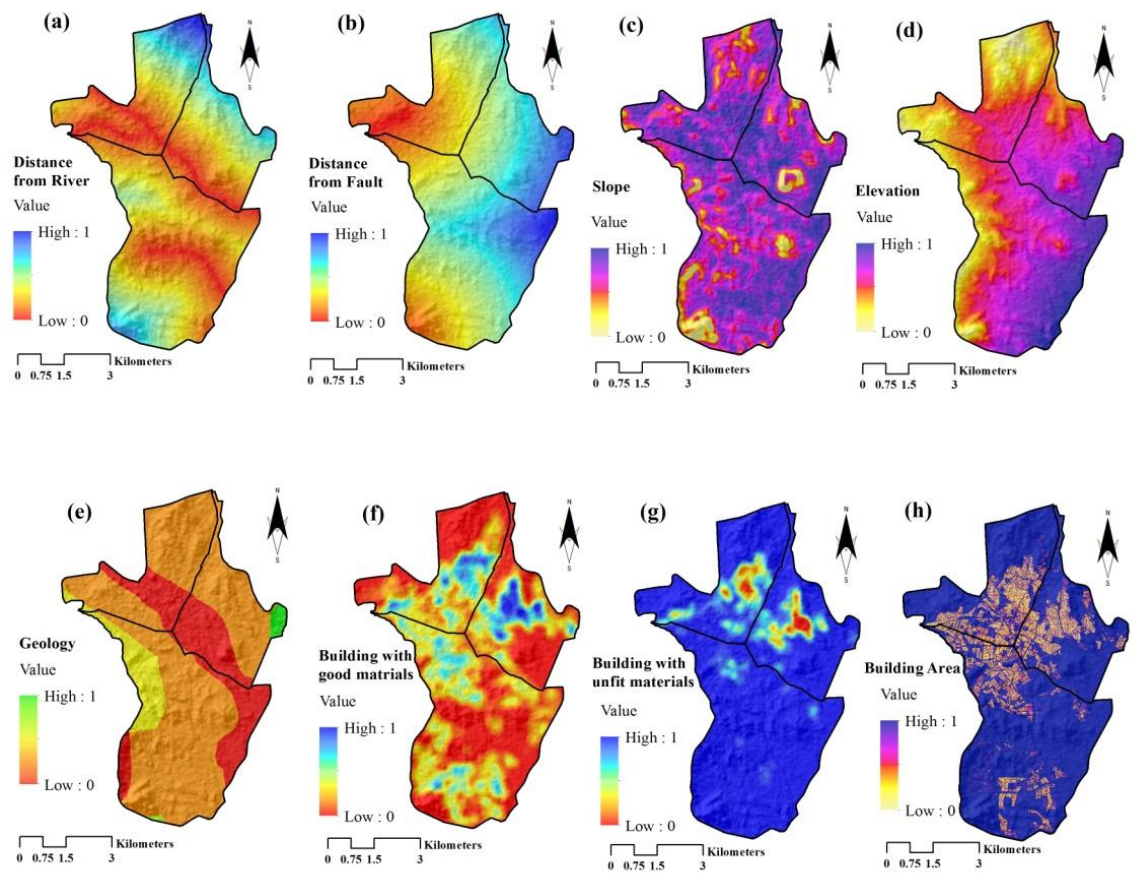

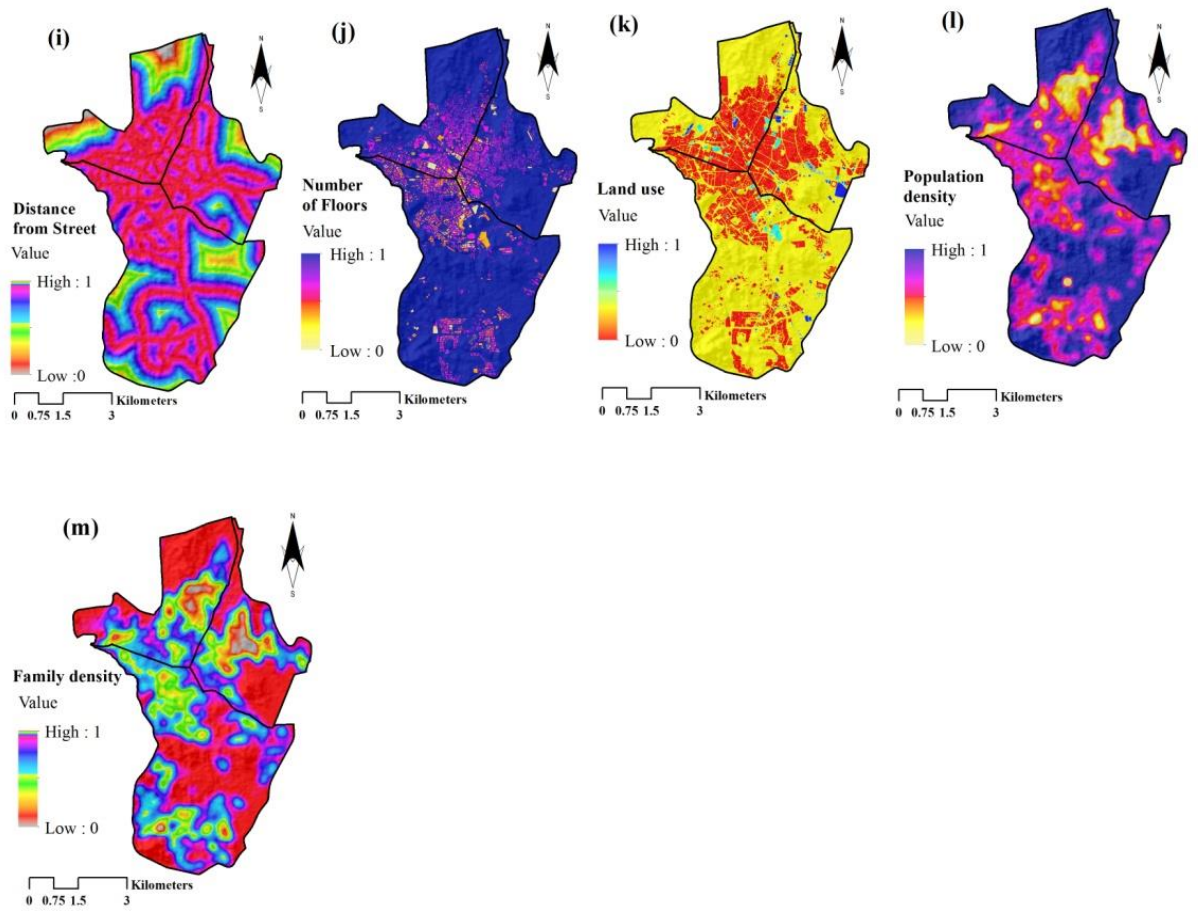

Figure 3. The Environmental, Physical, and Social layers used in the study.

\subsection{Artificial Neural Network (ANN)}

ANNs are numerical methods of artificial intelligence and their performance is the same as the human brain function, which can be used as a new technique for prediction and classification (Khawaja $\mathrm{M}$ et al., 2018).Artificial neural networks include a number of neural connections that have two input and output layers (Haykin,S., 2009). This computation network is able by receiving inputs,to provide accurate output information, for this reason in environmental risk assessment (Arabameri et al., 2019 \& Pece V. Gorsevski et al., 2016), therapeutic assessment (Shahid N et al., 2019 \& Mollalo .A et al., 2019) and etc have been used by many scholars as an efficient model.The model used in this study is the radial base function neural network $(\mathrm{RBFNN})$ and a type of artificial neural network, which are used in mathematical modeling of radial primary functions as active functions (Li, L et al., 2009). The RBFNN model has three layers of input, hidden and output, which nonlinear units are directly connected to each node in the input layer (N. S. Kumar et al., 2016). In many cases, this model can be used as a kernel in support vector classes (VanderPlas, Jake., 2015). The RBF neural network is a tridimensional model with optimal performance, which during processing of the task of the hidden layer, perform nonlinear transformations and the task of the output layer is performing linear transformations (Jinchao Li et al., 2018). In the other words, converting in the RBF model from the input layer to the nonlinear hidden layer and converting from the hidden layer to the output layer is linear (C.M. Lee., 2009). Also, the infrastructure of this network is robust enough to be used in engineering applications without any problems (Biancolini., 2018). The RBFNN model has a simple structure and easy to learn, which uses the base Gaussian radius function to activate the hidden neurons. The Gaussian radial base function will be as follows:

$$
R\left(x_{p}-c_{i}\right)=\exp \left(-\frac{1}{2 \sigma^{2}}\left\|x_{p}-c_{i}\right\|^{2}\right)
$$

Where $x_{p}=$ input to the hidden layer

$$
c_{i}=\text { Gaussian function center }
$$

II $x_{p}-c_{i} \|=$ distance from the entrance to the Gaussian function center

$$
\sigma=\text { Gaussian function variance. }
$$

Then, for mathematical modeling in "Terrset Geospatial Monitoring and modeling system" Software, of the radial base functional neural network (RBFNN) was used as a radial base function and one of the techniques of artificial neural networks. In the present study, the RBFNN is trained using supervised learning and during the training, a recursive update method is used to evaluate the RBFNN weight. In an RBF network, there are two sets of weights, the first weights connect the input layer to the hidden, and the other connects the hidden layer to the output layer. The weights that are connected to the input layer include the parameters of the base functions (Sarimveis, $\mathrm{H}$ et al., 2006).The output of the network is derived from: (G. CORSINI et al., 2003).

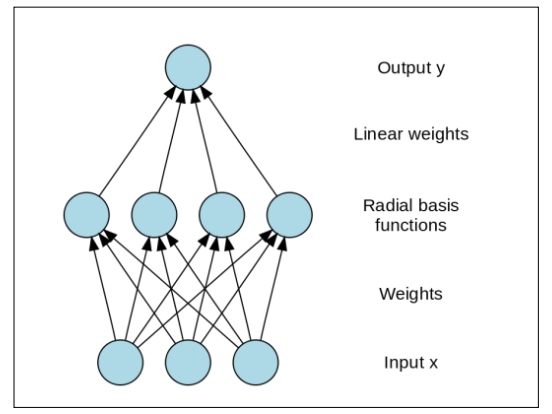

Figure 4. Architecture of a radial basis function network 


$$
f_{n}(x)=\sum_{i=1}^{k} w_{n i} \varphi_{i}(x)+w_{n 0}
$$

Where $\quad k=$ number of radial base functions

$x=$ the input vector

$w_{n i}=$ represents the relationship between the base function and the output layer

$$
\varphi_{1}=\text { radial basis function }
$$

\subsection{Application of AHP in this study}

The AHP model was originally proposed by Thomas L. Saaty and One of MCDM's methods for solving complex and nonstructural problems is by creating a functional hierarchy (T.L. Saaty., 1988). The AHP model is a common method for combining the factors, weight extraction and alternative decisions (P. Arulbalaji et al., 2019). In the present study, 13layers were selected. The layers are weighted according to the scale of relative importance of 1 to 9 based on the effect in Seismic vulnerability. After weighing the layers and creating the matrix of paired comparisons, the index of compatibility (CR) was obtained through principle Eigen value $(\lambda)$ and integrity index (CI).

$$
\lambda \max =\sum_{\mathrm{j}=1}^{\mathrm{n}}\left[\mathrm{W}_{\mathrm{j}} \sum_{\mathrm{i}=1}^{\mathrm{m}} \mathrm{a}_{\mathrm{ij}}\right] \quad, \quad 169 / 13=13
$$

Where $\quad a_{i j}=$ number of criteria in each column $\mathrm{W}_{\mathrm{j}}$ = weight belonging to each criterion

$C . I=\frac{(\lambda \max -\mathrm{n})}{(\mathrm{n}-1)} \quad, \quad \frac{(13-13)}{(13-13)}=0$

Where $n=$ number of factors used in the analysis and the compatibility index is defined by the relation

$C . R=C I / R \quad, C . R=0$

Where $\quad \mathrm{CI}=$ integrity index

$\mathrm{R}=$ Ratio index for values

If the $\mathrm{CR}$ value is 0 , then there is complete compatibility in the comparisons (T.L. Saaty., 1990).

\begin{tabular}{|c|cccccccccc|}
\hline $\mathrm{N}$ & 1 & 2 & 3 & 4 & 5 & 6 & 7 & 8 & 9 & 10 \\
\hline R.I & 0 & 0 & 0.58 & 0.90 & 1.12 & 1.24 & 1.32 & 1.41 & 1.45 & 1.49 \\
\hline
\end{tabular}

Table 2. Ratio index for values of $\mathrm{N}$

\begin{tabular}{|c|c|c|c|c|}
\hline Criteria & (a) & (b) & (c) & Weights \\
\hline Environmental (a) & 1 & - & - & 0.36 \\
Physical (b) & 0.77 & 1 & - & 0.47 \\
Social (c) & 2.12 & 2.76 & 1 & 0.17 \\
\hline
\end{tabular}

Table 3. Comparative matrix of the criteria used in the study and the obtained weights.

Then using the AHP model map in five vulnerability classes ,very low, Low, moderate, high and very high, created a database of training site, and in each class, 50 point were randomly selected.

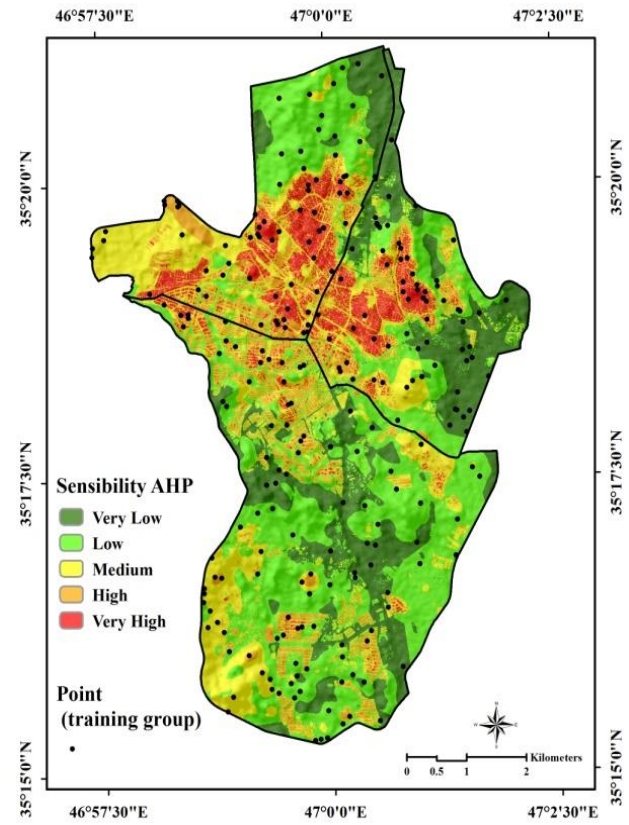

Figure 5. Training sites created via the AHP map

\section{Implementing the RBFNN Model}

\subsection{Transferring Layers to IDRISI Software}

After selecting the training sites from the layer containing the points and the 13 Raster layers, the output was taken in ENVI format and for implementing the RBFNN model, layers turned into 'idrisi' format. Since the input layers are classified, the sampling method was selected in the implementation of the model as a classification.

\begin{tabular}{|c|c|}
\hline Parameters & Input value \\
\hline Band image & 13 \\
Training site file & Image \\
Training sample & Random sampling \\
Sampling proportion & $70 \%$ \\
Number of radial basis function & 16 \\
P nearest neighbors & 2 \\
Percentage of migrating pixels & $1 \%$ \\
Maximum iterations & 50 \\
\hline
\end{tabular}

Table 4. Input parameters for implementing the RBFNN model 


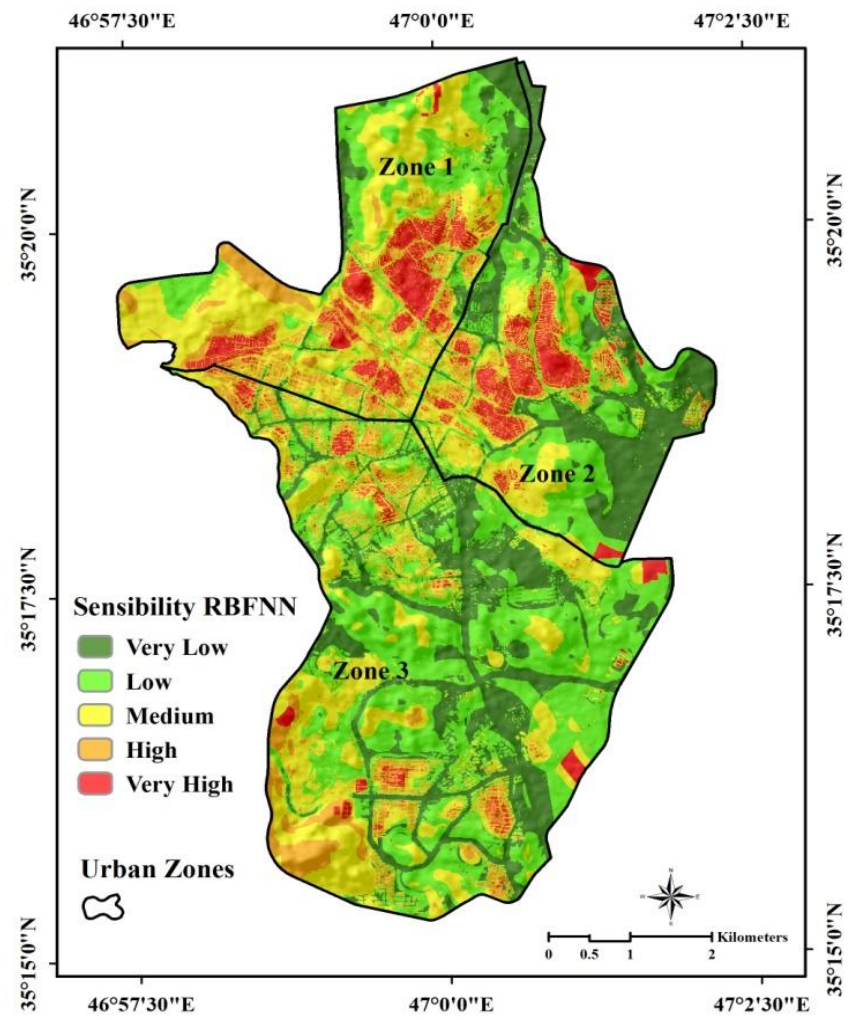

Figure 6. Seismic Vulnerability Map of Sanandaj City based on the RBFNN models

\subsection{Validation}

In order to validation the result of RBFNN model, the ROC curve was used. In this curve, AUC is a measure of the accuracy of a seismic vulnerability map, which is value ranges from 0 to 1. If its value goes to side 1 , the precision of the result of the model will be greater, and if it reaches 0 , accuracy will decrease. In this study, the value of the area under the curve (AUC) for the RBFNN model is 0.922 , which indicates the high accuracy of the model.

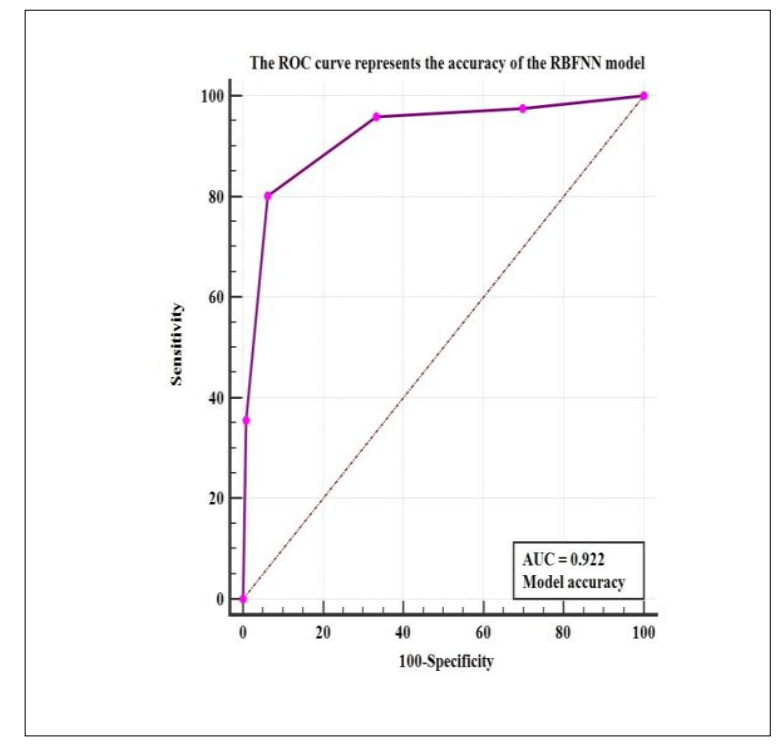

Figure 7. ROC curve for validation the result
of the RBFNN model.

Figure 7. ROC curve for validation
of the RBFNN model.

\section{Social and Physical vulnerability}

Since the main purpose of the study is to assess the social and physical vulnerability versus earthquake, in this section through seismic vulnerability map and demographic data, by performing SPATIAL JOIN and DISSOLVE functions the rate of social and physical vulnerability of Sanandaj city in the tables 5 and 6 is specified.

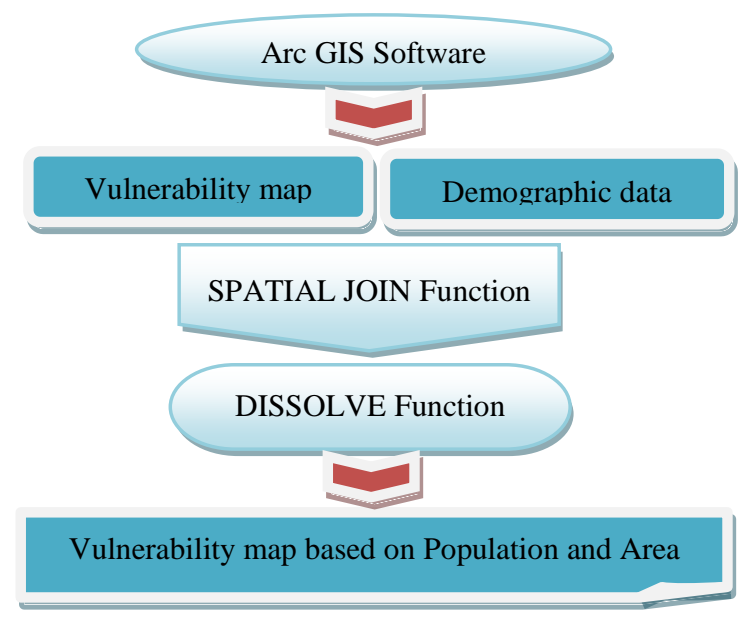

Figure 8 . The process of generating vulnerability maps based on population blocks 


\begin{tabular}{|c|c|c|c|c|c|c|c|}
\hline Damage range & Percentage & Population & Woman & Man & Tenant & Employed & Unemployed \\
\hline Very low & 5.13 & 2629 & 6600 & 6559 & 281 & 20166 & 5618 \\
Low & 26.45 & 20218 & 8449 & 7523 & 2527 & 20595 & 6167 \\
Moderate & 42 & 90305 & 25786 & 25012 & 11865 & 30012 & 8382 \\
High & 18.3 & 152551 & 83910 & 85068 & 18078 & 59891 & 19355 \\
Very High & 8.12 & 69104 & 42403 & 43497 & 8366 & 37506 & 12644 \\
\hline
\end{tabular}

Table 5. Sanandaj Social vulnerability based on the MCDA-RBFNN hybrid model.

\begin{tabular}{|c|c|c|c|c|c|c|c|}
\hline \multirow{2}{*}{ Damage range } & \multirow{2}{*}{ Area } & \multicolumn{3}{|c|}{ Land use } & \multicolumn{3}{c|}{ Materials } \\
\hline & & Educational & Clinic & Residential & Commercial & Strong & Weak \\
Very low & 2167600 & 1961 & 22 & 1275 & 608 & 956 & 302 \\
Low & 11176200 & 13681 & 294 & 10248 & 1828 & 7783 & 167 \\
Moderate & 17788200 & 44891 & 1444 & 39363 & 2048 & 30548 & 1004 \\
High & 7724100 & 143236 & 788 & 135780 & 4976 & 60063 & 7254 \\
Very High & 3401900 & 51498 & 26 & 49785 & 1428 & 26254 & 7778 \\
\hline
\end{tabular}

Table 6. Sanandaj Physical vulnerability based on the MCDA-RBFNN hybrid model.

\section{Conclusion}

By observating the result of the AHP-RBFNN hybrid model in order to assess the vulnerability of the City of Sanandaj against earthquake, it can be concluded that the use of the hierarchical analysis process to create training points can have impact on the ANN output. By validating $30 \%$ of the training points, the ANN map shows the social and physical high vulnerability of Sanandaj. According to table number (3), $42 \%$ of the total urban space is located in the middle class vulnerability. However, according to the results, the highest level of vulnerability is in urban areas 1 and 2 with high population densities and worn-out

\section{REFERENCE}

Abolfazl Mollalo., Liang Mao., Parisa Rashidi., Gregory E. Glass., 2019.A GIS-Based Artificial Neural Network Model for Spatial Distribution of Tuberculosis across the Continental United States. Int. J. Environ. Res. Public Health 2019, 16, 157.

Arabameri,A., Biswajeet Pradhan., Khalil Rezaei,. Chang-Wook Lee., 2019.Assessment of Landslide Susceptibility Using Statistical- and Artificial Intelligence-Based FR-RF Integrated Model and Multiresolution DEMs. Remote Sens. 2019, 11, 999; doi: 10.3390/rs11090999.

Alizadeh,M., Ibrahim Ngah., Mazlan Hashim., Biswajeet Pradhan., Amin Beiranvand Pour., 2018. A Hybrid Analytic Network Process and Artificial Neural Network (ANP-ANN) Model for Urban Earthquake Vulnerability Assessment. Remote Sens. 2018, 10, 975.

Behnaz RaheliNamin., Behrooz Mohseni., 2018. Integrated Artificial Neural Network Modeling and GIS for Identification of Important Factor on Groundwater Hydrochemistry. Arch Hyg Sci 2018, 7(2): 126133. texture, and it is essential to consider the restoration of houses in these areas. The results show that multi-dimensional vulnerability assessment, according to all available the criteria in the city can help planners to take preventive measures to reduce their mortality and economic losses. Also, based on the validation of the AHP-RBFNN hybrid model with a precision of 0.922 in the ROC curve, it can be concluded that construction of hybrid models based on artificial neural network will increase accuracy and can be used as base models for future Studies.

Biancolini., Marco Evangelos., 2018. Fast radial basis functions for engineering applications. Springer International Publishing. ISBN 9783319750118. OCLC 1030746230.

C. M. Lee., C. N. Ko., 2009. Time series prediction using RBF neural networks with a nonlinear time-varying evolution PSO algorithm. Neurocomputing, vol. 73, no. 1-3, pp. 449-460.

Dragana Nenadić., 2019. Ranking dangerous sections of the road using MCDM model. Decision Making: Applications in Management and Engineering, 2(1), 115-131.

G. CORSINI., M. DIANI., R. GRASSOM. DE MARTINO., P. MANTERO., S. B. SERPICO., 2003. Radial Basis Function and Multilayer Perceptron neural networks for sea water optically active parameter estimation in case II waters: a comparison, International Journal of Remote Sensing 24:20, 3917-3932.

German I. Parisi., Ronald Kemker., Jose L. Part., Christopher Kanan., Stefan Wermter., 2019. Continual Lifelong Learning with Neural Networks: A Review. Neural Networks (2019) https://doi.org/10.1016/j.neunet.2019.01.012. 
Hashemi.M., Ali Asghar Alesheikh., Mohammad Reza Zolfaghari., 2017. A GIS-based time-dependent seismic source modeling of Northern Iran. Earthq Eng \& Eng Vib (2017) 16: 33-45.

Haykin, S., 2009. Neural networks and learning machines. Prentice Hall/Pearson, New York (USA)

Ibrahim, R. M., Mushatat, S.A., Abdelmonem, M.G., 2015. City profile: Erbil. Cities, 14-25.

Jinchao Li., Shaowen Zhu., Qianqian Wu., Pengfei Zhang., 2018. A Hybrid Forecasting Model Based on EMD-GASVMRBFNN for Power Grid Investment Demand. Mathematical Problems in EngineeringVolume 2018, Article ID7416037, 17 pages, https://doi.org/10.1155/2018/7416037.

Khawaja, M. Asim., Adnan Idris., Talat Iqbal., Francisco Martinez-Alvarez., 2018. Earthquake prediction model using support vector regressor and hybrid neural networks.PLoS ONE,13(7):e0199004.https://doi.org/10.1371/journal.pone.0199 004.

Li, L., Ma, J and Wen, Q., 2009, Comparison of local transfer function classifier and radial basis function neural network with and without an exhaustively defined set of classes, International Journal of Remote Sensing, 30: 1, 85-96.

Murgante B., ID Salmani M., Molaei Qelichi M., Hajilo M., 2017. A multiple criteria decision-making approach to evaluate the sustainability indicators in the villagers' lives in Iran with emphasis on earthquake Hazard. Sustainability 2017; 9(8): 1-14.

N. S. Kumar., B. R. Shrinivasarao., P. S. Pai., 2016. Radial Basis Function Neural Network (RBFNN) Based Modeling in Liquified Petroleum Gas (LPG)-Diesel Dual Fuel Engine with Exhaust Gas Recirculation (EGR). Indian Journal of Science and Technology, Vol 9(45),

Oludare Isaac Abiodun., Aman Jantan., Abiodun Esther Omolara., Kemi Victoria Dada., Nachaat AbdElatif Mohamed., Humaira Arshad., 2018. State-of-the-art in artificial neural network applications: A survey. Heliyon. 2018 Nov; 4(11): e00938.

P. Arulbalaji., D. padmalal., K. sreelash., 2019. GIs and AHP techniques Based Delineation of Groundwater potential Zones: a case study from southern Western Ghats, India. Scientific RepoRts (2019) 9:2082.

Pece ,V. Gorsevski ., M. Kenneth Brown ., Kurt Panter ., Charles ,M. Onasch ., Anita Simic ., Jeffrey Snyder., 2016. Landslide detection and susceptibility mapping using LiDAR and an artificial neural network approach: a case study in the Cuyahoga Valley National Park, Ohio. Landslides (2016) 13:467-484DOI 10.1007/s10346-015-0587-0.

Pourghasemi,H.R., Amiya Gayen., Sungjae Park., Chang-Wook Lee., Saro Lee., 2018. Assessment of Landslide-Prone Areas and Their Zonation Using Logistic Regression, LogitBoost,and NaïveBayes Machine-Learning Algorithms. Sustainability 2018, 10, 3697.

Saaty, T.L., 1988. What is the analytic hierarchy process? Springer Berlin Heidelberg, pp. 109-121.
Saaty,T. L., 1990. Decision making for leaders: the analytic hierarchy process for decisions in a complex world. (RWS publications, 1990).

Salah Bouktif ., Ali Fiaz., Ali Ouni I., Mohamed Adel Serhani.,2018. Optimal Deep Learning LSTM Model for Electric Load Forecasting using Feature Selection and Genetic Algorithm: Comparison with Machine Learning Approaches”,Energies,2018,11,1636;doi:10.3390/en11071636.

Sarimveis, H., Doganis, P., Alexandridis, A., 2006. A classification technique based on radial basis function neural networks. Advances in Engineering Software, 37: 218-221.

Shahid N., Rappon T., BertaW., 2019.Applications of artificial neural networks in health care organizational decision-making: A scoping review.PLoS ONE 14(2): e0212356. https://doi.org/10.1371/journal.pone.0212356.

Vander Plas, Jake., 2015. Introduction to Support Vector Machines. [O'Reilly]. Retrieved 14 May 2015.

Yingying Tian., Chong Xu., Haoyuan Hong., Qing Zhou \& Duo Wang., 2019. Mapping earthquake-triggered landslide susceptibility by use of artificial neural network (ANN) models: an example of the 2013 Minxian(China) Mw 5.9 event. GEOMATICS, NATURAL HAZARDS AND RISK 2019, VOL. 10, NO. 1, 1-25

Z. C. Aye., M. Jaboyedoff., M. H. Derron., C. J. van Westen., H. Y. Hussin., R. L. Ciurean., S. Frigerio., A. Pasuto ., 2016. An interactive web-GIS tool for risk analysis: a case study in the Fella River basin, Italy. Nat. Hazards Earth Syst. Sci., 16, 85101,2016

Žydrūnė MORKŪNAITĖ., Darius KALIBATAS., Diana KALIBATIENE., 2019. A BIBLIOMETRIC DATA ANALYSIS OF MULTI-CRITERIA DECISION MAKING METHODS IN HERITAGE BUILDINGS. Journal of Civil Engineering and Management, 2019, 25(2): 76-99 77. 